\title{
An Empirical Evidence of Amanah Ikhtiar Malaysia (AIM) Microcredit Programme Participants' Quality of Life
}

\section{Zuraidah Mohamed Isa}

Faculty of Business and Administration, Universiti Teknologi MARA (UiTM), Kedah Branch, Sungai Petani, Kedah 08400, Malaysia

\begin{abstract}
Since the inception of microcredit programmes, various studies have been carried out to assess their impacts. Earlier studies seemed to highlight this on the participants' income and consequently poverty. However, recent impact studies of microcredit programmes have been looking into participants' quality of life. Thus, this study attempted to investigate the impact of Amanah Ikhtiar Malaysia's microcredit programme on the participants' quality of life and analyse the differences between the new and old participants. This study took on a different perspective by examining aspects of personal attitude, subjective norm, perceived behavioural control, as well as entrepreneurial intention and behaviour. In selecting the samples, a probability sampling (disproportionate stratified) technique was employed. The hypotheses were tested using cross-sectional data of 638 Amanah Ikhtiar Malaysia participants. The findings of the study showed that all the hypotheses were significant and supported, where there was significant influence between participants' personal attitude and entrepreneurial intention, participants' subjective norm and entrepreneurial intention, participants' perceived behavioural control and entrepreneurial intention, participants' perceived behavioural control and entrepreneurial behaviour, participants' entrepreneurial intention and entrepreneurial behaviour, including participants' entrepreneurial behaviour and participants' quality of life. On the contrary, the findings of the study revealed no difference in the quality of life between new participants and old participants. This study may contribute to the policy implications of Amanah Ikhtiar Malaysia's microcredit programme, especially in improving training

ARTICLE INFO

Article history:

Received: 23 February 2020

Accepted: 09 June 2020

Published: 25 December 2020

DOI: https://doi.org/10.47836/pjssh.28.4.46

E-mail address:

and guidance.

Keywords: Amanah Ikhtiar Malaysia's microcredit programme, entrepreneurial behaviour, entrepreneurial intention, perceived behavioural control, personal attitude, quality of life, subjective norm
\end{abstract}

zuraidah588@uitm.edu.my

ISSN: 0128-7702

e-ISSN 2231-8534 


\section{INTRODUCTION}

A microcredit programme is one of the most innovative tools in poverty alleviation. In the past, some literature argued on the negative impacts which microcredit programmes have on participants' quality of life. Some of the arguments pointed out that these programmes develop dependency syndromes to the participants, as well as, become a financial burden to them due to high interest rates and administrative rate charges. In time, however, quite a number of literature have started to discuss the positive and significant impacts of microcredit programmes on participants' lives. As a matter of fact, an abundance of studies indicated positive differences brought by the credits offered through such programmes like improved living conditions, education, health, savings, and income.

In support of this, Ghalib et al. (2011) discovered that microcredit programmes possessed the potentials to alleviate poverty. Other studies also showed that participants of microcredit programmes had performed well economically than those who did not participate in the programmes. For example, a study by Tilakaratna et al. (2005) found that compared to non-participants, microcredit enabled the participants to improve the assets, expenditure, and income of their households.

Aside from the above, it is believed that microcredit programmes are capable to improve the quality of life among the poor. The study by Ghalib et al. (2011) too indicated that some studies in Pakistan exhibited that such programmes had brought significant impacts on the quality of life. On the same note, Khandker (2005) investigated the impacts of microcredit programmes and discovered similar positive welfare effects on all credit-receiving households. Additionally, Morduch (2000) and Rahman and Hossain (1995) claimed that the microcredit programme allowed their clients to achieve a better quality of life. In short, it intrinsically suffices to mention that microcredit programmes still bring about positive contributions to the participants' income and lives. Henceforth, to some extent, microcredit programmes are still relevant in improving the poor society's quality of life.

While the achievements of microcredit institutions in enhancing the income of the poor and alleviating poverty should be much-admired, it appears that most of these studies concentrated their investigations on the economic impact of microcredit programmes. This in turn has raised another interesting question: does the microcredit programme has an impact on a broader development goal, which is the participants' quality of life? Indeed, this question is relevant as argued by Murphy (2015) who stated that the use of microcredit programmes was not only limited to poverty alleviation but might also include other dimensions of development goals. As a case in point, participants' quality of life is more prevalent than poverty alleviation in the impact study of microcredit programmes in Malaysia due to the country's reduced poverty rate which was reported to be less than 1\% in 2016 (Economics Planning Unit, 2015). Therefore, investigations of the impact of microcredit programmes on 
the participants must go beyond the poverty impact studies. With respect to this, greater attention must be given to improve the poor's quality of life.

Insofar, most of the studies mentioned earlier assumed a direct relationship between microcredit and participants' quality of life. Nevertheless, Hulme (2000) stated that there was either a direct or indirect effect between the impact of microcredit programmes and participants' quality of life. For this reason, this study attempted to investigate the impact of Amanah Ikhtiar Malaysia's microcredit programme on the participants' quality of life via a different perspective by examining the aspects of personal attitude, subjective norm, perceived behavioural control, plus entrepreneurial intention and behaviour on participants' quality of life. Furthermore, this study analysed the differences in quality of life between the new and old participants.

\section{THEORETICAL DEVELOPMENT}

In general, the intervention of something can affect behavioural change and practices that lead to the achievement of desired outputs. In other words, behavioural change may not be the end goal, but a transition after an intervention that may enhance the result of other outcomes. This can also be drawn from the money that the participants receive from the microcredit programmes in assisting them to become entrepreneurs and start doing businesses. As a result, they can improve their quality of life.

In reference to behavioural change model, it can be seen that there is quite a number of literature in which behavioural change is theorised and conceptualised. From past literature, the most widely cited and applied theory of planned behaviour was developed by Ajzen (1991), i.e., the Theory of Planned Behaviour (TPB). A search of the online database showed a large number of published studies using Ajzen's theory of planned behaviour. These studies addressed such areas relating to health and behaviour (Godin \& Kok, 1996), predicting dishonest action (Beck \& Ajzen, 1991), internet purchasing (George, 2004), understanding and predicting electronic commerce adoption (Pavlou \& Fygenson, 2006), self-identity (Sparks \& Shepherd, 1992), and many more.

The TPB proposes a model that predicts the occurrence of a particular behaviour; whereby this particular behaviour is intentional. As stated by Ajzen (2006), individual behaviour can be deliberative and planned. TPB is a useful method for identifying a particular influence on behaviour that could be targeted for a change. As stated by Ajzen (2006), human behaviour is directed by three main determinants. They are personal attitude, subjective norm, and perceived behavioural control (see Figure 1). Ajzen (2006) also added that personal attitude yielded either a favourable or unfavourable attitude toward the behaviour which were values of the behavioural outcomes. Subjective norms caused by perceived social pressure or by what other people think the person should do affect the person's perception (to engage or not to engage). In other words, the subjective norms are about the positive suggestions, 
encouragements, or even advice from people surrounding the participants with regards to whether they should engage in the entrepreneurial intention. Finally, perceived behavioural control is an individual's perceptions of his abilities or feelings of self-efficacy to perform a behaviour. These three main constructs were used to predict the intention to perform a behaviour.

Meanwhile, in relation to the quality of life, literature has also shown that microcredit programmes bring a great impact on participants' quality of life. Chowdhury and Bhuiya's (2004) study of microcredit programmes in Bangladesh revealed that such programmes had a positive impact on human well-being, survival rate, and schooling of children. Similarly, another study by Khandker (2005) on the microcredit programme's impact in Bangladesh had found that the welfare effect was also positive for all households receiving credits. Much later, Ghalib et al. (2011) stated that a few studies in Pakistan had shown that microcredit programmes contributed positively to the poor's quality of life. Their finding indicated that out of four dimensions of study, asset accumulation tends to be a better indicator of economic well-being. Later, Quraisy et al. (2017) reported that a microcredit programme of BaitulMaal Wat Tamwil (BMT) in Indonesia had a positive impact on its participants' quality of life. Henceforth, it intrinsically suffices to mention that microcredit programmes bring about positive contributions and improvement to the participants' quality of life.

To further support the above findings, Hossain (1988), Morduch (2000), and Rahman and Hossain (1995) claimed that microcredit programmes allowed their clients to achieve a better quality of life. Additionally, Hulme and Bhattacharya (1996) revealed the same result where they found that microcredit programmes helped improve the borrowers' well-being and standard of living by improving their income and food consumption.

In the past, Cummins (1996) proposed seven core domains of life in his study, namely material well-being, health, productivity, intimacy, safety, community, and emotional well-being. Deriving from this, Cummins (1996) was decisive with seven main domains - material well-being, health, productivity, intimacy, safety,

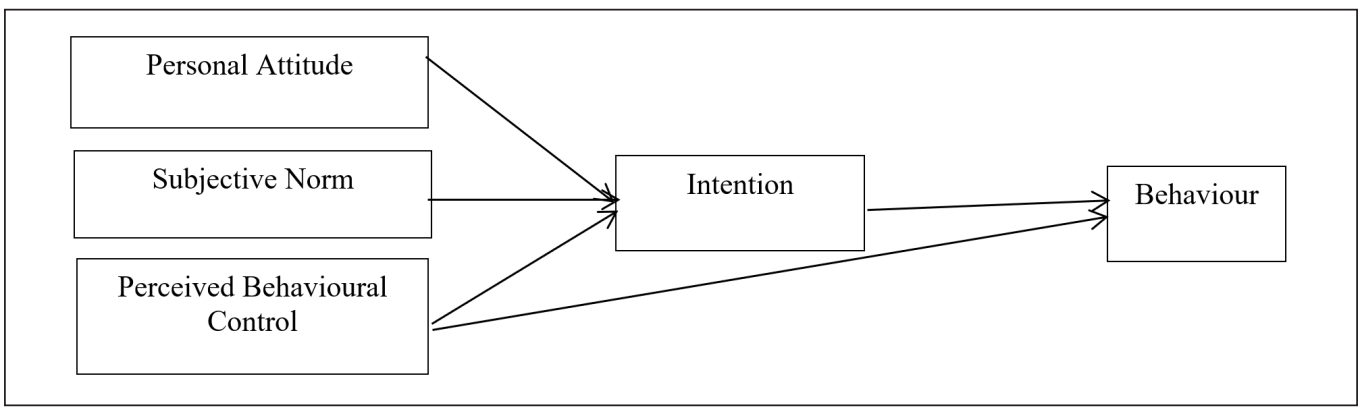

Figure 1. Ajzen's Model of Theory of Planned Behaviour 
community, and emotional well-being as important in assessing a person's quality of life. Cummins (1996) received favourable appraisal for his Comprehensive Quality of Life Scale (ComQol) where he stated that quality of life could be accessed through seven ComQol. Notwithstanding, his ComQol was abandoned in 2001 due to two main issues (Cummins, 2002). As a result of this, the Personal Wellbeing Index (PWI) was established to replace ComQol (The International Wellbeing Group, 2013). On the same matter, Malaysia introduced the Malaysian Quality of Life (MQL) in 1999 to examine the quality of life among Malaysians. The initial edition of the MQL index consisted of 10 components and 38 indicators. The more current version, however, consists of 11 components and 45 indicators. The components are income and distribution, working conditions, transport and communications, health, education, housing, environment, family life, social participation, public safety, as well as culture and leisure.
Nevertheless, due to its inability to effectively measure the impact of microcredit programmes on improving the participants' quality of life, a benchmark for the efficient measurement of microcredit programmes and participants' quality of life is urgently needed. Therefore, this study restructured the domains of life used in the key dimensions of PWI and MQLI to reflect the following dimensions: a) income earnings, b) health, c) productivity, d) friendship, e) personal safety, f) education, g) future security, h) food, i) housing conditions, j) personal savings, and $\mathrm{k}$ ) spirituality in measuring the participants' quality of life. The selection of these key dimensions was based on the available studies on microcredit programmes and participants' quality of life discussing these dimensions. Thus, the key dimensions chosen are deemed as most acceptable for future studies on quality of life.

From the TPB theory and quality of life index, a model of the impact chain by Hulme (2000) (see Figure 2) was adopted.

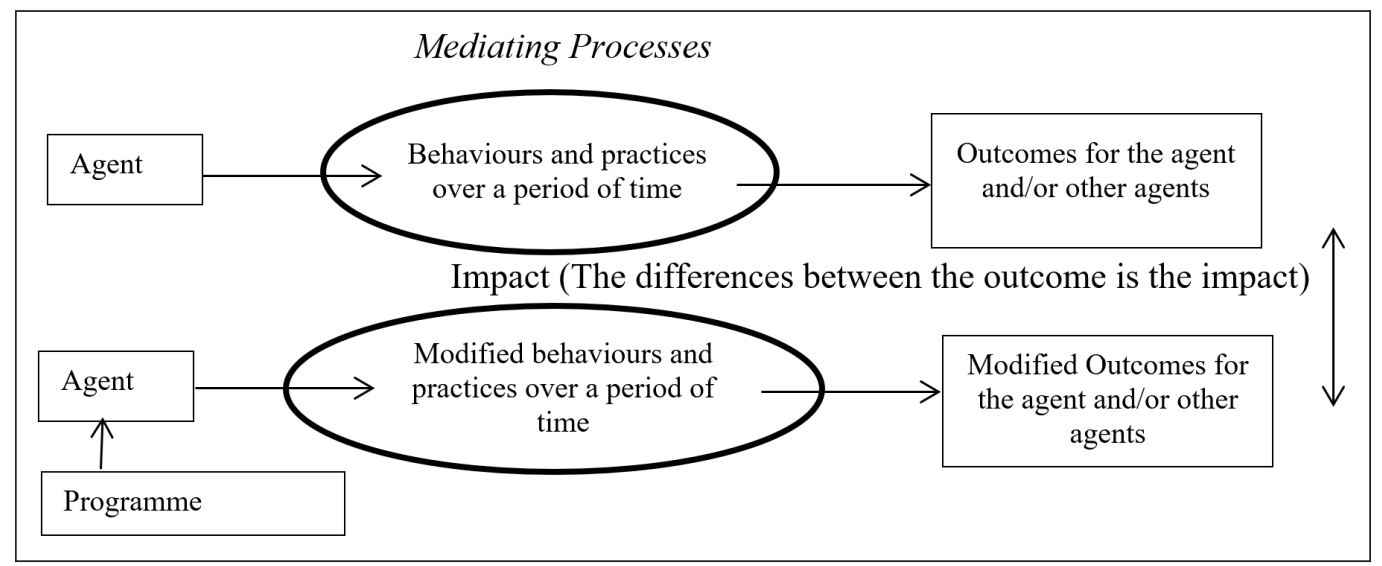

Figure 2. The conventional model of the impact chain

Source: Hulme (2000) 
Hulme's model describes that when the microcredit program is offered to the participants, it will possibly cause a change in participants' behaviours and practices that lead to the achievement of desired outputs. In other words, behavioural change may not be the end goal, but a transition after an intervention that may enhance the result of other outcomes.

Therefore, the TPB and the newly structured quality of life index were added into the model as established by Hulme (2000) to come up with the theoretical framework of this study as shown in Figure 3.

\section{HYPOTHESIS DEVELOPMENT}

A study by Ghalib et al. (2011) indicated that microcredit programmes had brought some positive impacts on the households' quality of life in Pakistan. The same result also appeared in a study conducted by Chowdhury and Bhuiya (2004), Hossain (1988), Hulme and Bhattacharya (1996), Morduch (2000), Rahman and Hossain (1995), and Khandker (2005) who claimed that microcredit programmes allowed their clients to achieve a better quality of life.

Similarly, a study by Afrane (2002) revealed an improvement in the respondents' well-being after they received financial assistance. Furthermore, a study by Epstein and Crane (2005) reported that microcredit programmes significantly impacted the client's quality of life. In 2011, A1Mamun and Adaikalam (2011) assessed the impact of microcredit programmes on participants' quality of life and concluded that participating in AIM microcredit programmes had indeed improved their life quality.

However, it appears that most of the above studies assumed a direct relationship between microcredit programmes and the quality of life of the participants. Therefore, this study argued that there are other factors that might influence the impact of microcredit programmes on participants' quality of life. These other factors are the participants' personal attitude, subjective norm, perceived behavioural control, as well as entrepreneurial intention, and entrepreneurial behaviour. In parallel to

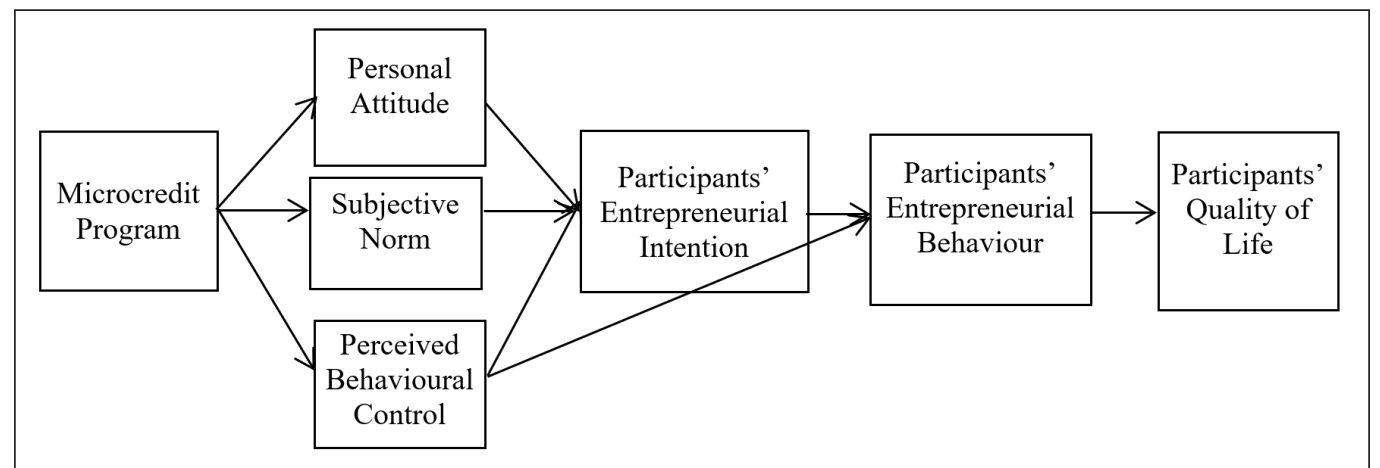

Figure 3. The theoretical framework of assessing the impact of a microcredit programme on participants' quality of life 
this, it is, therefore, hypothesised that microcredit programmes do have an impact on participants' quality of life.

For this study, a hypothesis (H1) was formulated to examine the impact of the microcredit programme on participants' quality of life:

a) H1a: Participants' personal attitude has a positive influence on participants' entrepreneurial intention.

b) H1b: Participants' subjective norm has a positive influence on participants' entrepreneurial intention.

c) H1c: Participants' perceived behavioural control has a positive influence on participants' entrepreneurial intention.

d) H1d: Participants' perceived behavioural control has a positive influence on participants' entrepreneurial behaviour.

e) H1e: Participants' entrepreneurial intention has a positive influence on participants' entrepreneurial behaviour.

f) H1f: Participants' entrepreneurial behaviour has a positive influence on participants' quality of life.

Furthermore, another hypothesis (H2) was also designed to analyse the differences in the quality of life of new and old participants. There are a number of studies that embarked on the same purpose. For example, a study conducted by Al-Mamun et al. (2010) reported that old participants seemed to have a better quality of life, where they tended to live in a bigger house with more rooms and better structural conditions, as well as used permanent housing materials to build their house. The study also revealed that compared to new participants, the old participants used environmentally less destructive cooking fuel and environmentally safe toilet facilities, as well as owned a refrigerator, a washing machine, and a television.

Consequently, analysing the differences in the quality of life of new and old participants will improve the understanding of the impact of microcredit programmes have on participants' quality of life. Thus, it was hypothesised that there are differences in the quality of life between new and old participants.

\section{RESEARCH METHOD}

\section{Population}

The population of this study was the participants of Amanah Ikhtiar Malaysia (AIM) in Kedah, Penang, and Perlis as at the end of 2013, 51,730 microcredit participants had been approved by Amanah Ikhtiar Malaysia (AIM) in these states. Based on this population, the minimum sample size required to conduct the research was 383 . As cited in Sekaran and Bougie (2009), and Krejci and Morgan (1970), the decision was to ensure a good decision model is simplified.

\section{Sampling Technique}

However, the sample size must be larger than the calculated sample responses required to overcome the sample attrition 
issue. Taking $80 \%$ as the estimated response rate as proposed by Mokhtar (2011), the calculated working sample size is required to avoid problems such as bias and incomplete responses. Henceforth, the appropriate sample size for this study was equivalent to 478 samples drawn from the total 51,730 participants. However, this study decided to distribute a total of 677 questionnaires to the participants of Amanah Ikhtiar Malaysia in Kedah, Penang, and Perlis (Table 1). To be more specific, 377 (55.69\%), 200 (29.54\%), and 100 (14.77\%) questionnaires were distributed to the participants of Amanah Ikhtiar Malaysia in Kedah, Penang, and Perlis, respectively. The number of distributed questionnaires was sufficient to address any future problems pertaining to sample error and missing error.

Through several meetings with the heads of selected branches, it was agreed that they would select suitable centres to distribute the questionnaires. Among the reasons why these centres were selected were because of various unaccepted conditions, such as lack of attendance among respondents to the stated meeting, the low literacy level among respondents in certain centres, centres with a too small number of respondents, centres conducting confidential meeting which did not permit other agenda, and centres which refused to cooperate in completing the questionnaires without any reason.

Furthermore, this study attempted to make a comparison of the quality of life between new and old participants of Amanah Ikhtiar Malaysia (AIM). In conjunction with this, the AIM participants were divided into two groups, old and new. Participants who took part less than or equal to 12 months were grouped into the new participants and those who took part more than 12 months were denoted as old participants.

However, as the researcher did not know the number of respondents who were new or old during the time of data collection, a disproportionate stratified sampling procedure was also employed. This was in line with the proposition by Sekaran and Bougie (2009) who posited the applicability of disproportionate sampling when the selected strata were too small or too large. Therefore, practically, this type of sampling technique enabled the study to distinguish between new and old participants under the programme. Thus, a disproportionate sampling method was an appropriate approach to select respondents from districts and groups to represent a sample.

Finally, the questionnaires were distributed during the Amanah Ikhtiar Malaysia weekly meeting and the researcher

Table 1

Sample size for Amanah Ikhtiar Malaysia participants in Kedah, Penang, and Perlis

\begin{tabular}{lccc}
\hline State & Number of AIM Participants as at the end of 2015 & Number of Samples & Number of Samples (\%) \\
\hline Kedah & 40,807 & 377 & 55.69 \\
Penang & 6,463 & 200 & 29.54 \\
Perlis & 4,460 & 100 & 8.58 \\
Total & 51,730 & 677 & 100 \\
\hline
\end{tabular}


instantly checked for any unanswered responses. As some of the respondents were not willing to participate in the survey, only 638 out of 677 questionnaires were received and usable for data analysis in this study. Although 39 incomplete questionnaires with a response rate of 94.24 percent $(638 / 677)$ were identified, the number was adequate and equivalent to previous studies which recorded response rates between 60 to 90 percent (Mokhtar, 2011). Thus, from the 638 completed questionnaires collected from the selected centres, 146 were recognised as new participants and 492 as old.

\section{Measurement}

The questionnaire development was adapted from the Personal Wellbeing Index (PWI), Liñán and Chen (2009), McGee et al. (2009), and Mokhtar (2011). Data were collected during the Amanah Ikhtiar Malaysia weekly meeting and the researcher instantly checked for any unanswered responses. In this study, all eleven items of participants' quality of life were assessed using an 11-point Likert Scale. In the same way, an 11-points Likert Scale was used to measure the participants' personal attitude, subjective norm, perceived behavioural control, as well as participants' entrepreneurial intention and behaviour in assessing the impact of microcredit programmes on their quality of life.

After the coding and editing process, data screening and cleaning were conducted. The final step was to conduct a descriptive analysis and an inferential analysis. Descriptive analysis was carried out using IBM SPSS Statistics 22 software while the inferential analysis was conducted using software SmartPLS version 3.0. PLS, which is a structural equation modelling (SEM) technique that tests both measurement model (relationships between indicators and their corresponding latent constructs or variables) and the structural model (relationships between the constructs or variables). This technique was considered adequate for the type of investigation carried out later.

\section{RESULT \\ Evaluation of Measurement Model}

In the measurement model evaluation, the convergent validity analysis was first examined. In order to assess the convergent validity, the factor loadings, composite reliability (CR), and average variance extracted (AVE) must be assessed (Hair et al., 2014a). Hence, for the present study, the factor loadings of all constructs were examined where .70 or more are considered acceptable (Hair et al., 2014a). Table 2 shows that all factor loadings were higher than .70. Therefore, all factor loadings in the study met the minimum requirement. Secondly, the composite reliability (CR) was assessed. According to Hair et al. (2014b), the composite reliability values of .60 and .70 are considered acceptable where any value less than .60 indicates a lack of composite reliability. Nunnally (1978), on the other hand, suggested the composite reliability values of .70 or higher for basic research. Table 2 displays the composite reliability (CR) values for all constructs that ranged from .927 to .975 which were 
Table 2

Results of convergent validity analysis

\begin{tabular}{|c|c|c|c|c|}
\hline Variables/Constructs & Items & $\begin{array}{c}\text { Factor Loading } \\
\text { (Loadings) } \\
(>.50)\end{array}$ & $\begin{array}{c}\text { Composite } \\
\text { Reliability (CR) } \\
(>.70)\end{array}$ & $\begin{array}{c}\text { Average Variance } \\
\text { Extracted (AVE) } \\
(>.50)\end{array}$ \\
\hline \multirow[t]{5}{*}{ Participants' Personal Attitude } & E1 & .853 & .961 & .831 \\
\hline & E2 & .923 & & \\
\hline & E3 & .915 & & \\
\hline & E4 & .942 & & \\
\hline & E5 & .922 & & \\
\hline \multirow[t]{2}{*}{ Participants' Subjective Norm } & F1 & .940 & .927 & .864 \\
\hline & F2 & .919 & & \\
\hline \multirow{5}{*}{$\begin{array}{l}\text { Participants' Perceived } \\
\text { Behavioural Control }\end{array}$} & G1 & .921 & .960 & .829 \\
\hline & $\mathrm{G} 2$ & .941 & & \\
\hline & G3 & .914 & & \\
\hline & G4 & .917 & & \\
\hline & G5 & .859 & & \\
\hline \multirow{4}{*}{$\begin{array}{l}\text { Participants' Entrepreneurial } \\
\text { Intention }\end{array}$} & $\mathrm{H} 1$ & .941 & .975 & .906 \\
\hline & $\mathrm{H} 2$ & .964 & & \\
\hline & H3 & .956 & & \\
\hline & $\mathrm{H} 4$ & .947 & & \\
\hline \multirow{4}{*}{$\begin{array}{l}\text { Participants' Entrepreneurial } \\
\text { Behaviour }\end{array}$} & D1 & .826 & .931 & .77 \\
\hline & D2 & .913 & & \\
\hline & D3 & .881 & & \\
\hline & D4 & .888 & & \\
\hline \multirow[t]{11}{*}{ Participants' Quality of Life } & $\mathrm{C} 2 \mathrm{~A}$ & .787 & .948 & .626 \\
\hline & $\mathrm{C} 2 \mathrm{~B}$ & .729 & & \\
\hline & $\mathrm{C} 2 \mathrm{C}$ & .809 & & \\
\hline & $\mathrm{C} 2 \mathrm{D}$ & .718 & & \\
\hline & $\mathrm{CDE}$ & .830 & & \\
\hline & $\mathrm{C} 2 \mathrm{~F}$ & .794 & & \\
\hline & $\mathrm{C} 2 \mathrm{G}$ & .846 & & \\
\hline & $\mathrm{C} 2 \mathrm{H}$ & .838 & & \\
\hline & C2I & .829 & & \\
\hline & $\mathrm{C} 2 \mathrm{~J}$ & .730 & & \\
\hline & $\mathrm{C} 2 \mathrm{~K}$ & .779 & & \\
\hline
\end{tabular}


within the acceptable values. Finally, the average variance extracted (AVE) of the constructs was measured. According to Hair et al. (2014a), the ideal value of AVE should be more than .50. Table 2 too exhibits the AVE values within the range of .626 to .906 , which met the minimal requirement of .50. From these assessments, the results showed that adequate convergent validity was achieved.

Once the convergent validity was assessed, the discriminant validity analysis was performed on the constructs. Discriminant validity is usually conducted to assess the extent to which a construct is different from one another. Ideally, it is conducted to compare the square root of the AVE values with the latent variable correlations, requiring the square root of each construct's AVE to be greater than its highest correlation with any other construct. In doing this, the cross-loading values are examined to establish support for the discriminant validity. Similarly, the Fornell-Larcker criterion is also examined to establish support for the discriminant validity. These are in line with the suggestions made by Hair et al. (2014b) and Chin (2010).

As a result, the cross-loading values obtained from the present study showed that the diagonal values were higher than the other values in the column and row. In the same way, the Fornell-Larcker criterion values also showed that the square roots of AVE in the diagonal setting were higher than the correlations with the other constructs. Therefore, the constructs in this study were considered as well-discriminated. Table 3 and Table 4 present the acceptable square root of AVE in the diagonal setting.

In a nutshell, all the assessments established that the construct reliability and the validity of the measurement model met the minimum requirement. As such, it could be assumed that the structural model evaluation was reliable and valid.

The determination coefficient $\left(\mathrm{R}^{2}\right)$ denoted the percentage of variance explained by the model. Table 5 shows the percentage of variance explained by the model. It could be seen that the percentage of variance explained was between the acceptable ranges.

\section{Evaluation of Structural Model}

There were six hypotheses developed to test the direct relationship. From the bootstrapping procedure, the hypotheses results were obtained and examined. Table 6 shows the final results that exhibited the standard beta values of the path analysis and displayed the $\mathrm{t}$-values of the path model significance.

Firstly, hypothesis H1a stated a positive and significant influence between participants' personal attitude and entrepreneurial intention, which was supported at a .01 level of significance $(b=.369, t=5.656, p<.01)$. Secondly, hypothesis $\mathrm{H} 1 \mathrm{~b}$ asserted a positive and significant influence between participants' subjective norm and participants' entrepreneurial intention, which was supported at .01 level of significance $(b=.154$, $\mathrm{t}=3.649 \mathrm{p}<.01$ ). Thirdly, hypothesis H1c 
Table 3

Results of cross loadings

\begin{tabular}{|c|c|c|c|c|c|c|}
\hline & $\begin{array}{c}\text { Participants' } \\
\text { Quality of } \\
\text { Life }\end{array}$ & $\begin{array}{c}\text { Participants' } \\
\text { Entrepreneurial } \\
\text { Behaviour }\end{array}$ & $\begin{array}{c}\text { Participants' } \\
\text { Personal } \\
\text { Attitude }\end{array}$ & $\begin{array}{c}\text { Participants' } \\
\text { Subjective } \\
\text { Norm }\end{array}$ & $\begin{array}{c}\text { Participants' } \\
\text { Perceived } \\
\text { Behavioural } \\
\text { Control }\end{array}$ & $\begin{array}{c}\text { Participants' } \\
\text { Entrepreneurial } \\
\text { Intention }\end{array}$ \\
\hline $\mathrm{C} 2 \mathrm{~A}$ & 0.787 & 0.534 & 0.500 & 0.419 & 0.523 & 0.379 \\
\hline $\mathrm{C} 2 \mathrm{~B}$ & 0.729 & 0.477 & 0.463 & 0.365 & 0.439 & 0.381 \\
\hline $\mathrm{C} 2 \mathrm{C}$ & 0.809 & 0.510 & 0.500 & 0.441 & 0.528 & 0.399 \\
\hline C2D & 0.718 & 0.500 & 0.500 & 0.467 & 0.511 & 0.421 \\
\hline $\mathrm{C} 2 \mathrm{E}$ & 0.830 & 0.485 & 0.513 & 0.435 & 0.489 & 0.445 \\
\hline $\mathrm{C} 2 \mathrm{~F}$ & 0.794 & 0.496 & 0.476 & 0.384 & 0.493 & 0.408 \\
\hline $\mathrm{C} 2 \mathrm{G}$ & 0.846 & 0.487 & 0.473 & 0.428 & 0.498 & 0.424 \\
\hline $\mathrm{C} 2 \mathrm{H}$ & 0.838 & 0.478 & 0.474 & 0.411 & 0.489 & 0.424 \\
\hline $\mathrm{C} 2 \mathrm{I}$ & 0.829 & 0.479 & 0.443 & 0.383 & 0.437 & 0.344 \\
\hline $\mathrm{C} 2 \mathrm{~J}$ & 0.730 & 0.460 & 0.402 & 0.351 & 0.443 & 0.348 \\
\hline $\mathrm{C} 2 \mathrm{~K}$ & 0.779 & 0.508 & 0.466 & 0.448 & 0.429 & 0.401 \\
\hline D1 & 0.518 & 0.826 & 0.608 & 0.441 & 0.560 & 0.504 \\
\hline D2 & 0.595 & 0.913 & 0.715 & 0.543 & 0.658 & 0.595 \\
\hline D3 & 0.515 & 0.881 & 0.608 & 0.441 & 0.615 & 0.553 \\
\hline D4 & 0.559 & 0.888 & 0.705 & 0.529 & 0.655 & 0.582 \\
\hline E1 & 0.534 & 0.676 & 0.853 & 0.550 & 0.655 & 0.575 \\
\hline E2 & 0.553 & 0.708 & 0.923 & 0.619 & 0.720 & 0.682 \\
\hline E3 & 0.575 & 0.666 & 0.915 & 0.651 & 0.701 & 0.736 \\
\hline E4 & 0.555 & 0.708 & 0.942 & 0.663 & 0.733 & 0.727 \\
\hline E5 & 0.525 & 0.681 & 0.922 & 0.684 & 0.723 & 0.744 \\
\hline F1 & 0.500 & 0.528 & 0.686 & 0.940 & 0.612 & 0.646 \\
\hline F2 & 0.471 & 0.510 & 0.606 & 0.919 & 0.582 & 0.558 \\
\hline G1 & 0.542 & 0.662 & 0.722 & 0.587 & 0.921 & 0.688 \\
\hline G2 & 0.552 & 0.667 & 0.738 & 0.597 & 0.941 & 0.702 \\
\hline G3 & 0.539 & 0.635 & 0.707 & 0.602 & 0.914 & 0.682 \\
\hline G4 & 0.575 & 0.684 & 0.719 & 0.598 & 0.917 & 0.705 \\
\hline G5 & 0.563 & 0.582 & 0.642 & 0.542 & 0.859 & 0.670 \\
\hline H1 & 0.518 & 0.620 & 0.718 & 0.624 & 0.730 & 0.941 \\
\hline H2 & 0.467 & 0.608 & 0.737 & 0.616 & 0.731 & 0.964 \\
\hline H3 & 0.480 & 0.605 & 0.741 & 0.626 & 0.728 & 0.956 \\
\hline H4 & 0.451 & 0.595 & 0.715 & 0.609 & 0.694 & 0.947 \\
\hline
\end{tabular}

indicated a positive and significant influence between participants' perceived behavioural control and participants' entrepreneurial intention, which was supported at a .01 level of significance $(b=.372, t=5.646, \mathrm{p}<.01)$.
Fourthly, hypothesis H1d pointed to a positive and significant relationship between participants' perceived behavioural control and participants' entrepreneurial behaviour, which was supported at a .01 
Table 4

Results of Fornell and Larcker Criterion

\begin{tabular}{|c|c|c|c|c|c|c|}
\hline & 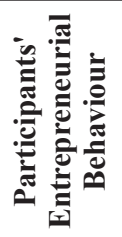 & 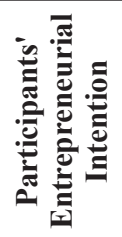 & 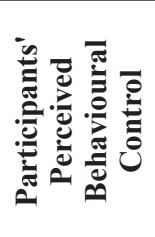 & 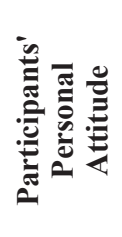 & 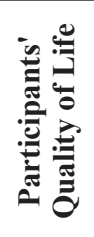 & 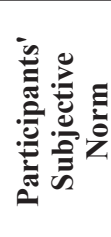 \\
\hline $\begin{array}{l}\text { Participants' } \\
\text { Entrepreneurial Behaviour }\end{array}$ & 0.878 & & & & & \\
\hline $\begin{array}{l}\text { Participants' } \\
\text { Entrepreneurial Intention }\end{array}$ & 0.638 & 0.952 & & & & \\
\hline $\begin{array}{l}\text { Participants' Perceived } \\
\text { Behavioural Control }\end{array}$ & 0.710 & 0.757 & 0.911 & & & \\
\hline $\begin{array}{l}\text { Participants' Personal } \\
\text { Attitude }\end{array}$ & 0.753 & 0.765 & 0.775 & 0.912 & & \\
\hline $\begin{array}{l}\text { Participants' Quality of } \\
\text { Life }\end{array}$ & 0.624 & 0.504 & 0.608 & 0.601 & 0.791 & \\
\hline $\begin{array}{l}\text { Participants' Subjective } \\
\text { Norm }\end{array}$ & 0.559 & 0.650 & 0.643 & 0.698 & 0.523 & 0.930 \\
\hline
\end{tabular}

Table 5

Results of Determination Coefficient $\left(R^{2}\right)$

\begin{tabular}{lcc}
\hline Constructs & $\mathbf{R}^{\mathbf{2}}$ & Predictive Power \\
\hline Participants' Entrepreneurial Intention & 0.664 & High \\
Participants' Entrepreneurial Behaviour & 0.528 & High \\
Participants' Quality of Life & 0.390 & High \\
\hline
\end{tabular}

Table 6

Results of hypotheses testing

\begin{tabular}{lllllll}
\hline $\begin{array}{c}\text { Hypothesis } \\
\mathbf{1}\end{array}$ & $\begin{array}{c}\text { Relationship (Exogenous-- } \\
\text { >Endogenous }\end{array}$ & $\begin{array}{c}\text { Standard } \\
\text { Beta }\end{array}$ & $\begin{array}{c}\text { Standard } \\
\text { Error }\end{array}$ & t-Values & p Values & Decision \\
\hline H1a & PA -> PEI & .369 & .065 & 5.656 & $.00 * * *$ & Supported \\
H1b & SN -> PEI & .154 & .043 & 3.649 & $.00 * * *$ & Supported \\
H1c & PBC -> PEI & .372 & .066 & 5.646 & $.00 * * *$ & Supported \\
H1d & PBC -> PEB & .533 & 0.047 & 11.434 & $.00 * * *$ & Supported \\
H1e & PEI -> PEB & .234 & .046 & 5.076 & $.00 * * *$ & Supported \\
H1f & PEB -> PQL & .624 & .030 & 20.927 & $.00 * * *$ & Supported \\
\hline
\end{tabular}

Note: $* * * \mathrm{p}<.01$

level of significance $(b=.533, t=11.434$, behaviour, which was supported at a .01 $\mathrm{p}<.01)$. Fifthly, hypothesis H1e established a level of significance $(b=.234, t=5.076$, positive and significant relationship between $\mathrm{p}<.01$ ). Finally, hypothesis H1f showed participants' entrepreneurial intention and that participants' entrepreneurial behaviour 
positively and significantly influenced the participants' quality of life at .01 level of significance $(b=.624, t=20.927, p<.01)$.

\section{Multi Group Analysis}

In this study, multi group analysis was also conducted to test the differences between path coefficients in the structural model across two groups of data. This was in line with Hair et al.'s (2014a) who claimed that a multi group analysis must be conducted to assess PLS path models between two groups to detect whether there were differences in parameter estimates for each group. In the context of this study, the different paths concerning the impact of AIM microcredit programme on its participants' quality of life can be revealed using the result of path coefficients across the two groups of data. As such, multi group analysis was conducted to observe the path coefficients across the two groups.

In order to conduct this assessment, the researcher divided the participants' length of years joining the AIM microcredit programme using SPSS analysis which created separate data sets of two groups; participants who joined the microcredit for less than one year (new participants $=146$ ) and participants who joined the microcredit for more than one year (old participants=492). A comparison between the new and old participants was analysed using the p-value.

Table 7 shows the results of multi group analysis in detail. Overall, the path coefficients between the two groups showed no difference in the quality of life of the new participants and the old participants. As shown in Table 7, the results of p-value at .181 indicated no significant difference in the effect of the participants' subjective norm on their entrepreneurial intention between the new participants and the old ones. Similarly, a p-value of .994 demonstrated no significant difference in the effect of the participants' perceived behavioural control on their entrepreneurial intention between the new participants and the old participants. In addition, the p-value at .881 indicated no significant difference in the effect of the participants' perceived behavioural control on their entrepreneurial

Table 7

PLS multi group analysis results in details

\begin{tabular}{lccccccc}
\hline & \multicolumn{2}{c}{$\begin{array}{c}\text { New Participants } \\
\text { (146 Respondents) }\end{array}$} & \multicolumn{2}{c}{$\begin{array}{c}\text { Old Participants } \\
\text { (492 Respondents) }\end{array}$} & & & \\
\hline & $\boldsymbol{\beta}$ & SE & $\boldsymbol{\beta}$ & SE & Diff & p-Value & sig \\
\hline PA -> PEI & .550 & .098 & .322 & .073 & .228 & .033 & $*$ \\
SN -> PEI & .219 & .080 & .134 & .047 & .085 & .181 & - \\
PBC -> PEI & .152 & .082 & .431 & .074 & .280 & .994 & - \\
PBC -> PEB & .446 & .084 & .564 & .053 & .117 & .881 & - \\
PEI -> PEB & .370 & .080 & .190 & .051 & .179 & .032 & $*$ \\
PEB -> PQL & .588 & .074 & .637 & .031 & .049 & .716 & - \\
\hline
\end{tabular}


behaviour between the new participants and the old. In fact, the results of p-value at .716 also revealed no significant difference in the effect of the participants' entrepreneurial behaviour on their quality of life between the new participants and the old participants.

Although the overall path coefficients between the two groups showed no difference in the quality of life between the new participants and the old participants, there were only two relationships (path coefficients) that differed significantly across the two groups.

\section{DISCUSSION}

This study attempted to investigate the impact of Amanah Ikhtiar Malaysia's microcredit programme on the participants' quality of life from a different perspective. The examined aspects involved personal attitude, subjective norm, perceived behavioural control, as well as entrepreneurial intention and behaviour. Besides, this study also analysed the differences in the quality of life between the new and the old participants.

In conjunction with investigating the impact of Amanah Ikhtiar Malaysia's microcredit programme on the participants' quality of life, the path coefficients were examined. Firstly, the result supported hypothesis H1a which states a positive and significant influence of participants' personal attitude on participants' entrepreneurial intention. This finding is in parallel with the studies by Autio et al. (2001), Engle et al. (2010), Fayolle et al. (2006), Liñán and Chen (2009), Karimi et al. (2012), and Krueger et al. (2000) who claimed that personal attitude had significant effects on entrepreneurial intention.

Secondly, the result confirmed there is a positive and significant influence of participants' subjective norm on their entrepreneurial intention as indicated by hypothesis H1b. This finding is consistent with findings by Autio et al. (2001), Engle et al. (2010), Fayolle et al. (2006), Liñán and Chen (2009), Karimi et al. (2012), and Krueger et al. (2000) who revealed that subjective norm had significant effects on entrepreneurial intention.

Thirdly, Hypothesis H1c indicates a positive and significant influence of the participants' perceived behavioural control on their entrepreneurial intention. This finding is in line with the findings of Autio et al. (2001), Engle et al. (2010), Fayolle et al. (2006), Liñán and Chen (2009), Karimi et al. (2012), and Krueger et al. (2000) who agreed that perceived behavioural control had significant effects on entrepreneurial intention.

Fourthly, H1d hypothesis affirmed that a positive and significant influence of participants' perceived behavioural control on their entrepreneurial behaviour as supported by the result. Evidently, findings by Autio et al. (2001), Engle et al. (2010), Fayolle et al. (2006), Liñán and Chen (2009), Karimi et al. (2012), and Krueger et al. (2000) are in accordance with the study's finding where they revealed that perceived behavioural control had significant effects on entrepreneurial intention.

Fifthly, Hypothesis H1e is in tandem with the result where it shows that there is a positive and significant influence of 
participants' entrepreneurial intentions on their entrepreneurial behaviour. This finding is parallel with the studies conducted by Autio et al. (2001), Engle et al. (2010), Fayolle et al. (2006), Liñán and Chen (2009), Karimi et al. (2012), and Krueger et al. (2000) which unveiled that participants' entrepreneurial intentions had significant effects on their entrepreneurial behaviour.

Lastly, the result showed a positive and significant influence of the participants' entrepreneurial behaviour on their quality of life, which is consistent with hypothesis H1f. Hulme (2000) claimed that microcredit will cause changes in participants' behaviour which would end in another outcome. By the same token, Darnton (2008) stated that behavioural change would affect a person's quality of life rather than being the end outcome. In fact, this is also in line with Nader (2008) who stated that self-esteem and confidence were enhanced through microcredit which led to improvement in the participants' quality of life.

From the above findings and discussion, it is concluded that microcredit programmes will have an impact on participants' quality of life through their personal attitude, subjective norm, perceived behavioural control, as well as entrepreneurial intention, and behaviour enhancements. Hence, microcredits are offered to participants of microcredit programmes for selfemployment activities. The microcredits promote positive personal attitude, subjective norm, perceived behavioural control, as well as entrepreneurial intention and behaviour that boost income-generating activities to improve the participants' quality of life and take care of themselves and their families.

While, in order to analyse the differences in the quality of life between the new and old participants, the multi group analysis was conducted. In line with this, hypothesis H2 was tested to meet the study's objective. When comparing the two groups, i.e., new participants who joined the microcredit programme for less than one year (new participants) and old participants who joined the microcredit programme for more than one year (old participants), it was found that there was no difference in their quality of life. This finding lies in stark contrast with a past study conducted by Al-Mamun et al. (2010) where they reported different qualities of life between the new and the old participants.

Although the researcher expected to see a different quality of life between the new participants who joined the microcredit programme for less than one year and the old participants who joined the microcredit programme for more than one year, the present findings indicated that the old participants who joined the microcredit programme for more than one year might insufficiently expand their potentials and opportunities to achieve a better quality of life.

\section{CONTRIBUTIONS OF THE STUDY}

AIM microcredit programme was established with the objective to reduce poverty among the households and provide low-income earners with microcredit 
facilities to improve their income earnings through income-generating activities. The establishment of the AIM microcredit programme was also with the objective to provide guidance and training to the poor. Despite the great achievement of the AIM microcredit programme, especially in poverty alleviation and improvement in the quality of life of the poor, this study revealed a new finding that suggests the need for further improvement in guidance and training in the programme.

The AIM microcredit programme is a great initiative for the poor. Therefore, this present study suggests for the AIM microcredit programme to set up and improve their training and development programmes for the participants. This is necessary to help facilitate the sustainable development of the participants. Providing participants with training and development programmes is compulsory because it is a significant strategy to monitor the effectiveness of the poverty alleviation strategy.

Discussion with experts from local universities may also help to facilitate the AIM's training and development programmes. Further discussion between AIM and the local universities should be conducted to see how the experts can bring a significant arrangement to the participants, especially in training and development programmes. AIM should take this opportunity as a continuing effort for a greater impact and sustainability.

On the other hand, an establishment of entrepreneurship mentoring programmes may also further increase the significance of AIM's training and development programmes. A mentoring entrepreneurship programme is a strategic concept of learning and development between mentors and mentees. The mentors will be able to help the mentees by advising and recommending necessary actions. This mentoring programme of entrepreneurship may perhaps help to contribute to the development of a talented pipeline for particular businesses among the participants.

\section{CONCLUSION}

The present study aimed to investigate the impact of Amanah Ikhtiar Malaysia's microcredit programme on the participants' quality of life via a different perspective by examining the aspects of personal attitude, subjective norm, perceived behavioural control, as well as entrepreneurial intention and behaviour. From the findings, all the reported hypotheses were significant and supported. In short, they were influential to the participants' quality of life.

Furthermore, this study also analysed the differences in the quality of life between the new and the old participants. However, the present findings revealed no difference. In conjunction with this, Amanah Ikhtiar Malaysia microcredit programme, on that front, falls short. In response to this, new guidance and training programmes for the participants should be implemented as motivational, professional, and emotional support. These are the key links for the old participants to not attempt on businesses merely for survival but also to ensure that they improve and increase their productivity 
for their business success. Therefore, the Amanah Ikhtiar Malaysia microcredit programme must initiate efforts for the sake of its participants.

\section{ACKNOWLEDGMENTS}

The researcher wishes to acknowledge the Ministry of Higher Education Malaysia for the funding and support of this paper.

\section{REFERENCE}

Afrane, S. (2002). Impact assessment of microfinance interventions in Ghana and South Africa: A synthesis of major impacts and lessons. Journal of Microfinance, 4(1), 37-58.

Ajzen, I. (1991). The theory of planned behaviour. Organizational Behaviour and Human Decision Processes, 50(2), 179-211. https://doi.org/10.10 80/08870446.2011.613995

Ajzen, I. (2006). Constructing a theory of planned behavior questionnaire. Retrieved November 23, 2020, from https://people.umass.edu/ aizen/pdf/ tpb.measurement.pdf

Al Mamun, A., \& Adaikalam, J. (2011). Empirical investigation on the effect of microfinance program of Amanah Ikhtiar Malaysia on quality of life in urban Peninsular Malaysia. European Journal of Economics, Finance and Administrative Sciences, (39), 101-1135.

Al Mamun, A., Abdul Wahab, S., Hossain, S., \& Malarvizhi, C. A. (2010). Impact of Amanah Ikhtiar Malaysia's microcredit schemes on hardcore poor households quality of life. International Research Journal of Finance and Economics, (60), 155-167. doi:10.2139/ ssrn. 1944375

Autio, E., Keeley, R. H., Klofsten, M., Parker, G. G. C., \& Hay, M. (2001). Entrepreneurial intent among students in Scandinavia and in the USA.
Enterprise and Innovation Management Studies, 2(2), 145-160. doi:10.1080/14632440110094632

Beck, L., \& Ajzen, I. (1991). Predicting dishonest actions using the Theory of Planned Behaviour. Journal of Research in Personality, 25(3), 285301 .

Chin, W. W. (2010). How to write up and report PLS analyses. In Handbook of Partial Least Squares (pp. 655-690). Berlin, Heidelberg: Springer. https://doi.org/10.1007/978-3-54032827-8_29

Chowdhury, A. M. R., \& Bhuiya, A. (2004). The wider impacts of BRAC poverty alleviation programme in Bangladesh. Journal of International Development, 16(3), 369-386. doi:10.1002/ jid. 1083

Cummins, R. A. (1996). The domains of life satisfaction: An attempt to order chaos. Social Indicators Research, 38(3), 303-328. https://doi. org/10.1007/BF00292050

Cummins, R. A. (2002). Vale ComQol: Caveats to using the comprehensive quality of life scale: Welcome the personal wellbeing index. Melbourne, Australia: Deakin University.

Darnton, A. (2008). GSR behaviour change knowledge review - Reference report: An overview of behaviour change models and their uses. Retrieved November 3, 2017, from https:// e1828c6e-07c7-4f4c-9b74-998c443f4819. filesusr.com/ugd/e28f7a_428142b1354c4c7282 54f6f51b083ab9.pdf

Economics Planning Unit. (2015). 11th Malaysia Plan 2016-2020: Anchoring growth on people. Retrieved November 3, 2017, from http:// www.pmo.gov.my/ dokumenattached/RMK/ RMK11_E.pdf.

Engle, R. L., Dimitriadi, N., Gavidia, J. V., Schlaegel, C., Delanoe, S., Alvarado, I., ... \& Wolff, B. (2010). Entrepreneurial intent: A twelvecountry evaluation of Ajzen's Model of 
Planned Behaviour. International Journal of Entrepreneurial Behaviour \& Research, 16(1), 3557. https://doi.org/10.1108/13552551011020063

Epstein, M. J., \& Crane, C. A. (2005). Alleviating global poverty through microfinance: Factors and measures of financial, economic, and social performance. In Business solutions for the global poor: Creating social and economic value (pp. 321-334). San Francisco, USA: Jossey-Bass.

Fayolle, A., Gailly, B., \& Lassas-Clerc, N. (2006). Effect and counter-effect of entrepreneurship education and social context on student's intentions. Estudios De Economia Alpicada, 24(2), 509-523.

George, J. F. (2004). The theory of planned behaviour and internet purchasing. Internet Research, 14(3), 198-212. https://doi. org/10.1108/10662240410542634

Ghalib, A. K., Malki, I., \& Imai, K. S. (2011). The impact of microfinance and its role in easing poverty of rural households: Estimations from Pakistan. Kobe University, 9(1), 1-37.

Godin, G., \& Kok, G. (1996). The theory of planned behaviour: A review of its applications to healthrelated behaviours. American Journal of Health Promotion, 11(2), 87-98. doi:10.4278/08901171-11.2.87

Hair, J. F., Hult, G. T. M., Ringle, C. M., \& Sarstedt, M. (2014a). Assessing PLS-SEM results part I. In A primer on Partial Least Squares Structural Equation Modelling (PLS-SEM) (pp. 95-166). New York, USA: Sage publications.

Hair, J. F., Hult, G. T. M., Ringle, C. M., \& Sarstedt, M. (2014b). Modeling heterogenous data. In A primer on Partial Least Squares Structural Equation Modelling (PLS-SEM) (pp. 243-281). New York, USA: Sage publications.

Hossain, M. (1988). Credit for alleviation of rural poverty: The Grameen Bank in Bangladesh (Vol. 65). New York, USA: Intl Food Policy Res Inst.
Hulme, D. (2000). Impact assessment methodologies for microfinance: Theory, experience and better practice. World Development, 28(1), 79-98. https://oi.org/10.1016/S0305-750X(99)00119-9

Karimi, S., Biemans, H. J. A., Lans, T., Mulder, M., \& Chizari, M. (2012). The role of entrepreneurship education in developing students' entrepreneurial intentions. In Proceeding of WICaNeM 2012, The 10th Wageningen International Conference on Chain and Network Science, Wageningen University, Wageningen, The Netherlands. http:// dx.doi.org/10.2139/ssrn.2152944

Khandker, S. (2005). Microfinance and poverty: Evidence using panel data from Bangladesh. The World Bank Economic Review, 19(2), 263-286. https://doi.org/10.1093/wber/lhi008

Krejcie, R. V., \& Morgan, D. W. (1970). Determining sample size for research activities. Educational and Psychological Measurement, 30, 607-610. https://doi.org/10.1177/001316447003000308

Krueger, N. F., Reilly, M. D., \& Carsrud, A. L. (2000). Competing models of entrepreneurial intentions. Journal of Business Venturing, 15(5), 411-432. https://doi.org/10.1016/S0883-9026(98)00033-0

Liñán, F., \& Chen, Y.-W. (2009). Development and cross-cultural application of a specific instrument to measure entrepreneurial intentions. Entrepreneurship Theory and Practice, 33(3), 593-617. https://doi.org/10.1111/j.15406520.2009.00318.x

McGee, J. E., Peterson, M., Mueller, S. L., \& Sequeira, J. M. (2009). Entrepreneurial self-efficacy: Refining the measure. Entrepreneurship Theory and Practice, 33(4), 965-988. https://doi. org/10.1111/j.1540-6520.2009.00304.x

Mokhtar, S. H. (2011). Microfinance performance in Malaysia (Unpublished doctoral thesis), Lincoln University, Christchurch, New Zealand.

Hulme, D., \& Bhattacharya, D. (1996). Credit for the poor in Bangladesh: The BRAC Rural 
Development Program and the Government Thana Resource Development and Employment Program. Finance Against Poverty, 2, 94-176.

Morduch, J. (2000). The microfinance schism. World Development, 28(4), 617-629. https://doi. org/10.1016/S0305-750X(99)00151-5

Murphy, T. (2015, January 22). Microfinance not a quick escape from poverty studies. Human Sphere. Retrieved November 22, 2020 , from https://www.humanosphere.org/socialbusiness/2015/01/microfinance-not-quickly-liftpeople-poverty-studies/

Nader, Y. F. (2008). Microcredit and the socioeconomic wellbeing of women and their families in Cairo. The Journal of Socio-Economics, 37(2), 644-656. https://doi.org/10.1016/j. socec. 2007.10 .008

Nunnally, J. C. (1978). Psychometric theory (2nd ed.). New York, USA: McGraw-Hill.

Pavlou, P. A., \& Fygenson, M. (2006). Understanding and predicting electronic commerce adoption: An extension of the theory of planned behaviour. MIS Quarterly, 30(1), 115-143. https://doi. org/10.2307/25148720
Quraisy, M., Hamzah, S., \& Razak, A. (2017). The impact of Islamic microfinance in enhancing the well-being and quality of life: Case study of Islamic financial cooperative (BMT) in Indonesia. South East Asia Journal of Contemporary Business, Economics and Law, 13(3), 1-12.

Rahman, H., \& Hossain, M. (Eds.). (1995). Rethinking rural poverty: Bangladesh as a case study. London, England: Sage Publications.

Sekaran, U., \& Bougie, R. (2009). Research methods for business: A skill building approach (5th ed.). New York, USA: John Wiley \& Sons Ltd.

Sparks, P., \& Shepherd, R. (1992). Self-identity and the theory of planned behaviour: Assessing the role of identification with "Green Consumerism". Social Psychology Quarterly, 55(4), 388-399. https://doi.org/10.2307/2786955

The International WellBeing Group. (2013). Personal wellbeing index - Adult (English) (5th ed.). Melbourne, Australia: Australian Centre on Quality of Life, Deakin University.

Tilakaratna, G., Wickramasinghe, U., \& Kumara, T. (2005). Microfinance in Sri Lanka: A household level analysis of outreach and impact on poverty. Colombo, Sri Lanka: Institute of Policy Studies of Sri Lanka. 